Annette Becker, Danielle Delmaire, Frédéric Gugelot (éds.), Juifs et chrétiens : entre ignorance, hostilité et rapprochement (1898-1998)?

Villeneuve d'Ascq, Édition du Conseil Scientifique de l'Université Charles-de-Gaulle-Lille 3, 2002, 254 p. (bibliogr.) (coll. « Travaux et Recherches »)

Anne-Sophie Lamine

\title{
CpenEdition
} Journals

Édition électronique

URL : http://journals.openedition.org/assr/771

DOI : 10.4000/assr.771

ISSN : $1777-5825$

Éditeur

Éditions de l'EHESS

Édition imprimée

Date de publication : 1 octobre 2003

Pagination : 63-170

ISBN : 2-222-96739-2

ISSN : 0335-5985

Référence électronique

Anne-Sophie Lamine, «Annette Becker, Danielle Delmaire, Frédéric Gugelot (éds.), Juifs et chrétiens entre ignorance, hostilité et rapprochement (1898-1998)?», Archives de sciences sociales des religions [En ligne], 124 | octobre - décembre 2003, document 124.2, mis en ligne le 24 octobre 2005, consulté le 24 septembre 2020. URL : http://journals.openedition.org/assr/771 ; DOI : https://doi.org/10.4000/assr. 771 
tombée du ciel ou œuvre d'artisan, que par les dons de vêtements, bijoux, cheveux qui donnent corps à la «communauté imaginée ». Ici le rapprochement que fait l'A., en notes, avec les fétiches africains rend bien compte de l'appropriation par les cités de «leur vierge » dont la fabrication de la couronne, assemblage de dons divers, est un élément emblématique.

Toutes ces marques d'habillages et d'individuation qui, l'A. en offre des exemples, peuvent donner à penser que la statue bouge, maigrit, réagit, bref se comporte comme une personne vivante, ont suscité les réserves du Concile de Trente et plus encore de synodes ultérieurs qui rejettent les habits profanes et prônent même clairement des statues dont les vêtements sont sculptés ou mieux encore des peintures. Ces recommandations et interdits n'ont pourtant guère influé sur les pratiques dont l'A. souligne la vivacité alors que dans l'Espagne postfranquiste la chute de la fréquentation dominicale se poursuit. Messe et procession ne relèvent pas de la même logique; pas plus que la vierge, reine de la cité, ne saurait se réduire aux attributs de la mère de Dieu. Dans un dernier chapitre, pour lequel il manque peutêtre une ou deux pages de transition, l'A. passe de la statue aux estampes qui en diffusent le vrai portrait et souligne un thème spécifique de l'iconographie mariale, ici exalté, celui de la Vierge au buisson d'épines. L'interprétation renvoie soit à l'arbre sec de Judée dont jaillit, miraculeuse, une rose, soit au buisson ardent qui brûle et ne se consume point, autre image de la vierge mère. Filant la métaphore de la rose et des épines, elle en montre les liens avec la pudeur des jeunes filles dont les habits sont hérissés d'épingles. Or en bien des rituels précisément la Vierge est considérée et traitée comme une jeune fille, en témoigne la longue chevelure bouclée dont elle est parée, et la manière dont on l'habille tend à faire disparaître son fils qui se confond avec elle. Ce statut de jeune fille idéale, vêtue parfois en mariée, éclaire encore d'une autre façon sa place dans les rites de passage des garçons et filles de ces cités.

$\mathrm{Au}$ fil de ces pages, l'A. ne se contente pas de faire revivre ces rites et fêtes mais s'attache toujours au sens des représentations et des pratiques. L'approche est ici attentive à restituer les soubassements des discours des acteurs et à mettre en valeur les enjeux sociaux et politiques des identités locales qui s'affirment par ce biais, et ne relèvent pas seulement d'un attachement à une mentalité magique. Pour autant elle ne gomme pas dans son étude de ces pratiques la dimension d'accès au surnaturel et la recherche d'une certaine forme de religiosité mystique, laquelle apparaît sans doute encore davantage aujourd'hui dans d'autres expériences liées aux nouvelles images miraculeuses (vierges ou christs pleurant ou saignant) qui ne reposent pas sur l'appartenance à une même communauté locale.

Isabelle Saint-Martin.

BECKER (Annette), DELMAIRE (Danielle), GUGELOT (Frédéric), éds.

Juifs et chrétiens : entre ignorance, hostilité et rapprochement (1898-1998) ? Villeneuve d'Ascq, Édition du Conseil Scientifique de l'Université Charles-de-Gaulle-Lille 3, 2002, 254 p. (bibliogr.) (coll. «Travaux et Recherches $»)$.

Cet ouvrage rassemble les contributions à un colloque organisé en novembre 1998, à l'Université de Lille 3. Il est composé de quatre parties correspondant aux différentes étapes du rapprochement entre juifs et chrétiens et d'une cinquième partie qui est le compte rendu d'une table ronde réunissant des acteurs pionniers des relations judéo-chrétiennes.

La première partie, intitulée « la découverte de l'autre », traite de la fin du XIX $^{\mathrm{e}}$ siècle aux années 1920. Elle est marquée par l'affaire Dreyfus et un antisémitisme catholique majoritaire. Les positions de l'Église catholique et en particulier du Vatican, avec Pie IX, évoluent à la fin du XIX ${ }^{\mathrm{e}}$ siècle vers l'affirmation de l'antisémitisme et la diffusion de la thèse du complot juif contre le catholicisme (G. Micolli). Il y eut cependant une « poignée de catholiques dreyfusards » qui dans leur lutte contre l'antisémitisme se basent à la fois sur la Déclaration des Droits de l'Homme et sur les arguments religieux de la filiation du christianisme à l'égard du judaïsme et dénoncent les accusations fantaisistes comme celles de la profanation d'hostie (D.D.). Du côté protestant, le philosémitisme d'un nombre significatif de protestants au tournant du siècle, découle davantage d'une mémoire des persécutions, d'un sens de la justice et du sentiment d'être eux-mêmes menacés que d'une réelle connaissance du judaïsme et de ses écrits (P. Harismendy). Parmi les précurseurs catholiques du philosémitisme, comme Leon Bloy, la réhabilitation du peuple juif n'est pas sans ambiguïtés. Les Maritain, l'abbé Journet et le Père Menasce, héritiers de Bloy, reprennent à leur manière cette vision du « mystère d'Israël » (Ph. Chenaux). Du côté juif, cette période est marquée par l'adoption d'une façon occidentale-chrétienne de s'approprier le temps. L'Aufklärung juive va 
métaphoriser le messianisme, permettant une historicisation de la culture juive. Le groupe sort de son isolement et affirme la complexité de son identité (J. Ehrenfreund).

La deuxième partie, intitulée «l'estime envers l'autre », traite de la période de l'entredeux-guerres. La Première Guerre mondiale semble d'abord consacrer l'intégration des juifs dans la nation, par le sacrifice de leurs morts. Les commémorations rappellent «l'œcuménisme [judéo-chrétien] des tranchées ». Cependant, les mouvements antisémites ne disparaissent pas, ils retrouvent une influence significative à partir des années 1930 (A.B.). En 1926 la très philosémite association des Amis d'Israël est fondée à Rome. Son but est la prière pour les juifs et l'apostolat en vue de leur conversion. De nombreux prêtres et prélats en sont membres. Cependant, l'attitude trop positive, voire enthousiaste, de son fondateur envers le judaïsme, alliée à son indépendance vis-à-vis de ses supérieurs, conduit à un décret d'interdiction du Saint-Office, dès 1928, faisant néanmoins mention de la condamnation de l'antisémitisme (M. Macina). La presse catholique des années 1930 condamne globalement l'antisémitisme (en général avec force, mais plus mollement dans La Croix), tout en gardant un certain nombre de stéréotypes sur les israélites. L'idée d'une parenté entre les deux religions est largement partagée, comme l'est aussi la conviction que l'accomplissement du destin juif reste dans la conversion au christianisme (R. Schor). Dans cette même période, la Revue Internationale des Sociétés Secrètes (RISS), organe d'un catholicisme intégral et intransigeant, développe le thème du complot judéo-maçonnique et diffuse son antisémitisme, certes moins violent que celui de Je suis partout (C. Thoinet). Si le cas du judéo-catholique André Paillère (1875-1949), fervent défenseur du noachisme est tout à fait singulier, il ne fut pourtant pas sans influence sur les relations judéo-catholiques. Sans renier son christianisme, Paillère se met totalement au service du judaïsme, par son enseignement de la pensée juive, ses écrits, ses prédications, son implication dans les structures du judaïsme libéral, ainsi que par les contacts qu'il favorise entre des personnalités juives et chrétiennes (C. Poujol).

La troisième partie, intitulée « la solidarité et l'amitié », correspond aux années 1940 et 1950. La période de guerre a favorisé les conversions. Mais il faut distinguer celles des adultes qui peuvent correspondre à un parcours ancien, accéléré par l'urgence, de celles des enfants sauvés par des institutions catholiques, qui étaient encouragés à la fois par protection et par conviction prosélyte et qui semblent avoir concerné quelques pour-cents des sauvetages (F.G.). Une question se pose : comment et quand a-t-on eu connaissance de l'extermination des juifs ? Pendant un an, entre l'été 1941 et l'été 1942, très peu d'informations diffusent, même si l'opinion s'émeut des rafles (Y.M. Hilaire). L'historien juif laïque Jules Isaac dont la famille a été victime de cette extermination, se met à écrire sur les origines de l'antisémitisme et à militer pour un « enseignement de l'estime », ainsi que pour le développement des relations judéo-chrétiennes. Il sera le principal fondateur de l'Amitié JudéoChrétienne en 1948 et rencontrera le Pape Jean XXIII en 1960 pour lui demander que l'antisémitisme et l'enseignement de l'estime soient traités dans le Concile (C. Iancu). Au tournant des années 1950, l'Affaire Finaly va empoisonner les relations judéo-chrétiennes. Deux enfants juifs ont été sauvés par une catholique qui refuse ensuite de les rendre à leur famille, et les fait baptiser. L'affaire durera de 1945 à 1953 et sera portée en justice. Elle divisera aussi l'opinion catholique sur la question de la liberté religieuse (A.D. Rinckwald). Du côté de la pensée théologique catholique sur le judaïsme, même si quelques précurseurs avaient montré leur solidarité et leur respect au moment de la montée du nazisme, c'est au moment du second Concile que l'approche théologique du peuple juif est réexaminée. $\mathrm{Ce}$ changement théologique sera donc bien une conséquence de la Shoah (J. Dujardin).

La quatrième partie, intitulée « la reconnaissance officielle », couvre la période 1960-1998. La rédaction de la partie de la déclaration conciliaire Nostra aetate concernant les juifs s'apparente à un parcours du combattant dont les étapes se déroulent de 1960 (visite d'Isaac) à 1965 (dernière assemblée du concile). Les principaux obstacles sont la crainte du soutien au sionisme du côté arabe, celle de la volonté de conversion du côté juif et les restes d'antisémitisme chrétiens (É. Fouilloux). On pourrait croire les relations judéo-catholiques pacifiées après le Concile, mais en 1985 l'affaire du Carmel d'Auschwitz éclate : des sœurs s'installent dans un bâtiment du camp, pourtant classé depuis 1979 dans le patrimoine mondial de l'UNESCO. Ce geste est perçu par les juifs comme une volonté de christianiser la Shoah, alors que de nombreux Polonais sont favorables au Carmel. Les crises, négociations et compromis se succèdent, pour aboutir au départ des carmélites (B. Delpal). Trois autres évènements marquent les relations judéo-catholiques au tournant du millénaire: la déclaration de repentance d'évêques français à Drancy (1997), 
la visite du cardinal Lustiger à la synagogue de New York (1998) et la prière de pardon du Pape, à Rome, puis au Mur des Lamentations (2000) (É. Poulat).

La cinquième partie est une table-ronde présidée par P. Pierrard et rassemblant cinq " témoins du rapprochement entre juifs et chrétiens ", deux prêtres, un pasteur, un rabbin et un juif laïque. Le père Demann a participé à la Conférence de Seelisberg (1947) et a montré que la catéchèse du tournant des années 1950 était encore imprégnée d'antisémitisme. Le pasteur Maury évoque la lenteur des prises de consciences de l'antisémitisme et observe qu'on donne beaucoup d'attention aux actions institutionnelles, au détriment des engagements personnels, comme ceux des équipiers de la CIMADE. Le père Dujardin souligne la lenteur de la diffusion des déclarations sur le judaïsme au sein du catholicisme. L'ancien président du CRIF, Théo Klein s'interroge sur le caractère « un peu hégémonique de l'Eglise catholique » et évoque les négociations d'Auschwitz auxquelles il a participé. Le grand-rabbin Sirat revient sur les difficultés jalonnant les relations judéo-chrétiennes en rappelant que comme grand-rabbin, il avait dû prendre position au moment de la nomination de l'archevêque de Paris, qui s'était affirmé juif et chrétien, pour souligner qu'il était impossible d'être les deux à la fois.

On peut certes regretter (avec É. Fouilloux, Conclusion) que «le projecteur [ait] été braqué sur la position des autorités catholiques, de personnalités catholiques et de l'opinion catholique face au judaïsme et aux juifs », laissant peu de place aux acteurs juifs et protestants. Cependant, on ne peut que se réjouir de la parution de cet ouvrage qui offre une vue d'ensemble de l'évolution des relations judéochrétiennes de la fin du XIX ${ }^{\mathrm{e}}$ à la fin du $\mathrm{XX}^{\mathrm{e}}$ siècle, dont les étapes et les enjeux sont remarquablement clarifiés.

\section{Anne-Sophie Lamine.}

\section{3}

BIRGE (Bettine).

Women, Property, and Confucian Reaction in Sung and Yüan China (960-1368). Cambridge (G.-B.), Cambridge University Press, 2002, xxii +345 p. (cartes, illustr., bibliogr., index-glossaire avec caract. chinois) (« Cambridge Studies in Chinese History, Literature, and Institutions $»)$.

Comme on aimerait que tous les travaux de sociologie historique concernant une civilisation exotique sache aussi bien que celui-ci intéresser, par des fresques générales, le sociologue et l'ethnologue et, par ses développements techniques précis, enrichir finement la connaissance du pays concerné. Une introduction d'une quarantaine de pages bien fournie, des conclusions partielles à chaque sous-section et chapitre et une conclusion finale d'une quinzaine de pages cernent en effet tous les aspects du problème concerné : le droit des femmes mariées à disposer de leur personne et de leurs biens propres et en fait ressortir magistralement l'évolution. Quatre chapitres chronologiques, abondamment nourris d'excellentes traductions des sources et de commentaires d'une clarté parfaite, donnent vie à la théorie, rapidement des origines au $\mathrm{X}^{\mathrm{e}}$ siècle, puis longuement sous la dynastie nationale des Song (Song du Nord de 960 à 1127, Song du Sud de 1127 à 1276/1279) et sous celle des Mongols gengiskhanides, les Yuan (du règne de Qubilai en 1260 à l'expulsion des Mongols en 1368). Quelques répétitions sont inévitables d'un chapitre à l'autre, mais elles sont visibles seulement pour qui prend la peine de lire l'ouvrage de bout en bout ; or ce n'est pas à ce seul lecteur consciencieux que le travail est destiné et, en tout cas, lui aussi prend plaisir à se sentir bien conduit dans les méandres des rapports officiels chinois, des règlements, des disputes entre lettrés, des affaires pénales, pour en retirer tout le suc.

Jusqu'à l'époque Song, la morale confucéenne, telle qu'on l'observe dans les valeurs prônées par l'élite, dans les codes de lois, dans les rituels et les textes philosophiques, évolua pour s'adapter aux changements de la société. L'unité économique et sociale passa, de l'idéal antique de la grande famille patrilinéaire, à la cellule familiale formée des frères et de leurs femmes autour des parents du mari, garçons et filles ayant droit à une part d'héritage. De telle sorte que chaque épouse issue d'une famille à l'aise jouissait, au sein de son ménage, d'un bien propre, sa dot, et à la mort de son mari, si celui-ci était le chef de famille, de la haute main sur l'ensemble des possessions familiales du couple (chap. 1).

À l'époque Song, sous la pression de la commercialisation de l'économie et des possibilités d'un enrichissement rapide, les femmes acquirent une indépendance économique encore plus grande. Les juges (et les pères de famille) prirent l'habitude d'attribuer aux filles une portion de l'héritage, qui, sous les Song du Sud, était égale à la moitié de celle de leurs frères. Lorsqu'un ménage n'avait pas de fils au décès du mari et était ce qu'on appelait un foyer interrompu (hujue), un moyen de prolonger la lignée était de désigner un agnat du mari comme 